\title{
AUDIOLOGICAL PROFILE IN PATIENTS WITH DIABETES MELLITUS
}

\author{
Sheila Raman Kutty1, Balakrishnan Edacheriyan², Vinayak ${ }^{3}$, Lata Mary4 \\ ${ }^{1}$ Associate Professor, Department of ENT, Academy of Medical Sciences, Pariyaram, Kannur, Kerala. \\ 2 Professor, Department of ENT, Academy of Medical Sciences, Pariyaram, Kannur, Kerala. \\ ${ }^{3}$ Resident, Department of ENT, Academy of Medical Sciences, Pariyaram, Kannur, Kerala. \\ ${ }^{4}$ Senior Resident, Department of ENT, Academy of Medical Sciences, Pariyaram, Kannur, Kerala.
}

ABSTRACT

\section{BACKGROUND}

Two hundred known diabetic patients who satisfied the selection criteria and consented were included in the study. Sample technique used was consecutive sampling. Data collection technique and tools were through a detailed ENT examination, fasting and postprandial blood sugar estimation and pure tone audiometry. The study was done at a tertiary care hospital and a hospitalbased cross-sectional study design was employed.

The aim of the study was to know the association between the severity of sensorineural hearing loss, the duration of diabetes mellitus and the diabetic status.

\section{MATERIALS AND METHODS}

Two hundred known diabetic patients were included in the study. Sample technique used was consecutive sampling. Data collection technique and tools were through a detailed ENT examination, fasting and postprandial blood sugar estimation and pure tone audiometry. A hospital-based cross-sectional study design was employed. Statistical Analysis: Statistical analysis was performed using the Statistical Package for Social Sciences (SPSS). Data collected was analysed using descriptive statistical methods like frequencies, percentages, mean and standard deviation. Results were presented in the form of both tables and graphs. An inferential statistical tool like chi-square test was used. The test was considered significant at $\mathrm{p}<0.05$.

\section{RESULTS}

Severity of sensorineural hearing loss was high among the cases with greater duration of Diabetes mellitus. The prevalence of sensorineural hearing loss was more in patients having uncontrolled diabetic status (94.6\%) compared to patients having controlled diabetic status (20.9\%). In patients with diabetes of less than 5 years group, the prevalence of sensorineural hearing loss was $10.6 \%$. In 5 to 10 years duration group, the prevalence was $38.6 \%$. In 10 to 15 years duration group, the prevalence was $69.2 \%$. In more than 15 years duration group, it was $78.9 \%$. The prevalence of sensorineural hearing loss was more in patients having uncontrolled diabetes status (94.6\%) compared to patients having controlled diabetic status (20.95). Severity was also high among uncontrolled diabetic group.

\section{CONCLUSION}

It was found that greater the duration of diabetes, greater is the prevalence of sensorineural hearing loss. In less than 5 years duration group, prevalence was $10.6 \%$. In 5 to 10 years duration group, prevalence was $38.6 \%$. In 10 to 15 years duration group, prevalence was $69.2 \%$. In more than 15 years duration group, it was $78.9 \%$. Severity of sensorineural hearing loss was also high among the cases with greater duration of diabetes mellitus. The prevalence of sensorineural hearing loss was more in patients having uncontrolled diabetic status (94.6\%) compared to patients having controlled diabetic status (20.9\%). Severity was also high among uncontrolled diabetic group.

\section{KEYWORDS}

Pure Tone Audiometry, Sensorineural Hearing Loss, Diabetes Mellitus.

HOW TO CITE THIS ARTICLE: Kutty SR, Edacheriyan B, Vinayak, et al. Audiological profile in patients with diabetes mellitus. J. Evolution Med. Dent. Sci. 2017;6(65):4691-4694, DOI: 10.14260/Jemds/2017/1015

\section{BACKGROUND}

Diabetes mellitus is a chronic metabolic disorder due to relative or absolute lack of insulin, which result in elevated blood sugar levels. Morbidity in Diabetes mellitus is mainly due to long-term micro- and macro-vascular complications affecting blood vessels of eyes, kidneys, heart and nerves. The

Financial or Other, Competing Interest: None.

Submission 28-07-2017, Peer Review 09-08-2017,

Acceptance 11-08-2017, Published 14-08-2017.

Corresponding Author:

Dr. Sheila Raman Kutty,

Department of ENT,

Academy of Medical Sciences,

Pariyaram, Kannur, Kerala.

E-mail: sheelaent@yahoo.com

DOI: $10.14260 /$ jemds $/ 2017 / 1015$ relationship between diabetes mellitus and hearing loss has been debated for many years. It has been postulated that the microvascular and neuropathic complications of diabetes do affect the hearing of individuals. Studies in animals have demonstrated thickening of the basement membrane of capillaries of stria vascularis.(1)

Diabetes mellitus has been implicated as independent causative factor of sensorineural hearing loss. Most audiometric studies of hearing in patients of diabetes show a mild-to-moderate sensorineural hearing loss mostly in high frequency,(2) although Celik et al(3) noted high threshold at all frequencies tested in diabetics.

In view of contradictory results regarding hearing impairment in diabetic patients, this study was done to assess the hearing threshold level in diagnosed patients of diabetes mellitus to study the correlation between the degree of 
sensorineural hearing loss and the duration, severity of diabetes mellitus and its complications.

Panchu found that all the frequencies (250 to $8000 \mathrm{~Hz}$ ) were affected in poorly controlled diabetics, that is glycosylated haemoglobin (HbA1c) $>8 \%$, while examining the auditory acuity in type 2 diabetes mellitus in an Indian population.

Asma et al failed to establish any association between the type of treatment given and the effect on hearing thresholds in their study on conventional oral hypoglycaemic agents versus insulin therapy on pure tone average. (4)

In a study conducted by Sheetal Krishnappa et al (2015), prevalence of hearing loss was high in type 2 diabetic patients $(73 \%)$. Bilaterally symmetrical progressive SNHL with right sloping curve was seen in both diabetics as well as non-diabetics with hearing loss noted at all frequencies, but significantly in higher frequencies in diabetics.

However, a significant relationship was observed between $\mathrm{HbA1c}$, blood sugar level and severity of hearing loss. The severity increased as the duration of diabetes increased.(5) In a study conducted by Hamid Abdul Qaiyum et al (2015) in 50 diabetics and non-diabetics, the pure tone audiometric test revealed that 13 (26\%) diabetic cases were having mild-to-moderate sensorineural hearing loss as against $4(8 \%)$ non-diabetic controls. It is concluded that the diabetic patients have significantly high incidence of sensorineural hearing loss when compared to non-diabetic control group of comparable age.(6)

In a study conducted by Ashish C Agarwal et al (2015) in 40 diabetic patients, majority of the patients had bilateral sensorineural hearing loss ranging in severity from minimal to mild degree. Median pure tone average (PTA) values were less in patients with good glycaemic status as compared to those with poor glycaemic status.

OAEs were absent in $30 \%$ of subjects. Age had a contributing effect on raising the hearing threshold, but gender and duration of diabetes did not show such an effect. (7)

The current study aimed to document the prevalence of sensorineural hearing loss in diabetes mellitus and the association between the duration of diabetes mellitus and severity of sensorineural hearing loss.

\section{MATERIALS AND METHODS}

A hospital-based cross-sectional study was carried out from March 2014 to 2015. Institutional Ethical Committee approval was taken for the study. Total 200 consecutive diabetic patients (type 1 and type 2) of either gender visiting the outpatient department of medicine patients were included in the study. They were diagnosed to have diabetes mellitus according to the criteria given by the American Diabetes Association. (8)

Inclusion criteria included diabetic patients were in the age limit between 30 - 55 years and patients willing to undergo the investigations.

Exclusion criteria included patients were outside the age limit of 30 - 55 years. Patients not willing to undergo pure tone audiometry testing, patients with a history of ear discharge, perforated tympanic membrane or any chronic ear discharge, history of intake of ototoxic drugs continuously for 6 months and prolonged history of exposure to noise (e.g. Industrial workers) were excluded from the study.
Besides detailed history, all the patients underwent an otoscopic examination, biochemical and routine urine investigations such as postprandial blood (PPBS), fasting blood sugar (FBS), serum urea and creatinine and urine for sugar, protein, ketones and microalbuminuria was obtained prior to the start of the study.

Pure tone audiometry was carried out in a sound treated room for the estimation of hearing threshold using a double channel GSI clinical audiometer. Pure tone thresholds were obtained at an octave between frequencies of 250 and 8000 $\mathrm{Hz}$ for air conduction and 250 and $4000 \mathrm{~Hz}$ for bone conduction.

Statistical package for social sciences (SPSS) was used to analyse the data. The data obtained was presented in the form of tables, figures, graphs and diagrams wherever necessary. An interferential statistical tool like chi-square test was used. The test was considered significant at $p<0.05$.

\section{RESULTS}

The hospital-based cross-sectional study was carried out in 200 cases who were already diagnosed as having diabetes mellitus. The parameters that were studied are as follows:

1. SNHL and duration of diabetes.

2. Severity of SNHL and duration of DM.

3. SNHL and status of diabetes.

4. Severity of SNHL and status of DM.

\section{SNHL and Duration of Diabetes}

In our study, the subjects were divided into 4 groups on the basis of duration of diabetes. It is found that greater the duration of diabetes, greater is the prevalence of SNHL. The duration of DM is a significant factor responsible for SNHL in diabetics (chi-square test, $\mathrm{p}$ value $<0.001$ ).

\section{Severity of SNHL and Duration of DM}

Among the cases with duration of DM $<5$ years 76 (89.4\%) cases were having normal hearing out of total 85 cases, 8 cases were having mild SNHL (9.4\%) and 1 case was having moderate SNHL (1.2\%). Among the cases with duration of DM of 5 - 10 years, 43 cases $(61.4 \%)$ were having normal hearing. Out of 70 cases, 25 cases were having mild SNHL (35.7\%) and 2 cases were having moderate SNHL (2.9\%). Among the cases with duration of DM of 10 - 15 years, 8 cases $(30.8 \%)$ were having normal hearing. Out of total 26 cases 6 cases were having mild SNHL (23.1\%), 6 cases were having moderate SNHL $(23.1 \%)$ and 6 cases were having moderately severe SNHL (23.1\%). Among the cases with duration of DM > 15 years 4 cases $(21.1 \%)$ were having normal hearing out of total 19 cases, 2 cases were having mild SNHL (10.5\%), 6 were having moderate SNHL (31.6\%), 5 cases were having moderately severe SNHL (26.3\%) and 2 cases were having severe SNHL (10.5\%).

\section{SNHL and Status of Diabetes}

In our study among the 200 subjects, 37 had uncontrolled diabetes and 163 had controlled diabetes. Among the uncontrolled, 35 (94.6\%) had SNHL. Among controlled group, 34 (20.9\%) had SNHL. On statistical analysis, the status of DM is a significant factor responsible for SNHL in diabetics (chisquare test, $\mathrm{p}$ value $<0.001$ ) 


\section{Severity of SNHL and Status of Diabetes}

Out of total 200 cases, 163 cases were having controlled diabetic status and 37 cases were having uncontrolled diabetic status. Among the 163 cases of controlled DM, 129 cases $(79.1 \%)$ were having normal hearing status, 30 cases were having mild SNHL (18.4\%) and 4 cases were having moderate SNHL (2.5\%). Among the 37 cases of uncontrolled DM 2 cases $(5.4 \%)$ were having normal hearing, 11 cases were having mild SNHL (29.7\%), 11 cases were having moderate SNHL (29.7\%), 11 cases were having moderately severe SNHL (29.7\%) and 2 cases (5.4\%) were having severe SNHL. More severe type of SNHL is seen among uncontrolled diabetic group.

\begin{tabular}{|c|c|c|c|}
\hline $\begin{array}{c}\text { DM Duration } \\
\text { Group }\end{array}$ & Subjects & $\begin{array}{c}\text { Subjects } \\
\text { with SNHL }\end{array}$ & Prevalence \\
\hline < 5 Years & 85 & 9 & $10.6 \%$ \\
\hline 5-10 Years & 70 & 27 & $38.6 \%$ \\
\hline $10-15$ Years & 26 & 18 & $69.2 \%$ \\
\hline$>15$ Years & 19 & 15 & $78.9 \%$ \\
\hline \multicolumn{2}{|c|}{ Table 1. SNHL and Duration of Diabetes } \\
\hline
\end{tabular}

\begin{tabular}{|c|c|c|c|c|c|c|}
\hline $\begin{array}{c}\text { DM } \\
\text { Duration }\end{array}$ & $\begin{array}{c}\text { Total } \\
\text { Cases }\end{array}$ & Normal & $\begin{array}{c}\text { Mild } \\
\text { SNHL }\end{array}$ & $\begin{array}{c}\text { Moderate } \\
\text { SNHL }\end{array}$ & $\begin{array}{c}\text { Moderate } \\
\text { Severe } \\
\text { SNHL }\end{array}$ & $\begin{array}{c}\text { Severe } \\
\text { SNHL }\end{array}$ \\
\hline$<5$ Years & 85 & $\begin{array}{c}76 \\
(89.4 \%)\end{array}$ & $\begin{array}{c}8 \\
(9.4)\end{array}$ & $1(1.2 \%)$ & 0 & 0 \\
\hline $\begin{array}{c}5-10 \\
\text { Years }\end{array}$ & 70 & $\begin{array}{c}43 \\
(61.4 \%)\end{array}$ & $\begin{array}{c}25 \\
(35.7 \%)\end{array}$ & $2(2.9 \%)$ & 0 & 0 \\
\hline $\begin{array}{c}10-15 \\
\text { Years }\end{array}$ & 26 & $\begin{array}{c}8 \\
(21.1 \%)\end{array}$ & $\begin{array}{c}6 \\
(23.1 \%)\end{array}$ & $\begin{array}{c}6 \\
(23.1 \%)\end{array}$ & $\begin{array}{c}6 \\
(23.1 \%)\end{array}$ & 0 \\
\hline $\begin{array}{c}>15 \\
\text { Years }\end{array}$ & 19 & $\begin{array}{c}4 \\
(21.1 \%\end{array}$ & $\begin{array}{c}2 \\
(10.5 \%)\end{array}$ & $\begin{array}{c}6 \\
(31.6 \%)\end{array}$ & $\begin{array}{c}5 \\
(26.3 \%)\end{array}$ & $\begin{array}{c}5 \\
(10.5 \%)\end{array}$ \\
\hline \multicolumn{7}{|c|}{ Table 2. Severity of SNHL and Duration of DM } \\
\hline
\end{tabular}

\begin{tabular}{|c|c|c|c|}
\hline DM Status & Cases & Cases with SNHL & Prevalence \\
\hline Controlled & 163 & 34 & $20.9 \%$ \\
\hline Uncontrolled & 37 & 35 & $94.6 \%$ \\
\hline \multicolumn{3}{|c|}{ Table 3. SNHL and Status of Diabetes } \\
\hline
\end{tabular}

\begin{tabular}{|c|c|c|c|c|c|c|}
\hline $\begin{array}{c}\text { DM } \\
\text { Status }\end{array}$ & $\begin{array}{l}\text { Total } \\
\text { Cases }\end{array}$ & Normal & $\begin{array}{l}\text { Mild } \\
\text { SNHL }\end{array}$ & $\begin{array}{c}\text { Moderate } \\
\text { SNHL }\end{array}$ & $\begin{array}{c}\text { Moderate } \\
\text { Severe } \\
\text { SNHL }\end{array}$ & $\begin{array}{c}\text { Severe } \\
\text { SNHL }\end{array}$ \\
\hline Controlled & 163 & $\begin{array}{c}129 \\
(79.1 \%)\end{array}$ & $\begin{array}{c}30 \\
(18.4 \%)\end{array}$ & $\begin{array}{c}4 \\
(2.5 \%)\end{array}$ & 0 & 0 \\
\hline Uncontrolled & 37 & $\begin{array}{c}2 \\
(5.4 \%)\end{array}$ & $\begin{array}{c}11 \\
(29.7 \%)\end{array}$ & $\begin{array}{c}11 \\
(29.7 \%)\end{array}$ & $\begin{array}{c}11 \\
(29.7 \%)\end{array}$ & $\begin{array}{c}2 \\
(5.4 \%)\end{array}$ \\
\hline \multicolumn{7}{|c|}{ Table 4. Severity of SNHL and Status of Diabetes } \\
\hline
\end{tabular}

\section{DISCUSSION}

The relationship between diabetes mellitus and sensory neural hearing loss is complex and under debate since many years supported by the bulk of conflicting literature. The crux about the effect of diabetes in SNHL lies centered around the cochlea and the neural pathways, which has been studied throughout the years in relation to duration of DM and glycaemic levels.
There is a strong correlation between the duration of diabetes and SNHL in our study. Those who are having more than 15 years of DM had a high prevalence of SNHL (78.9\%). In the group with duration of $\mathrm{DM}<5$ yrs., prevalence is only $10.6 \%$. The duration of DM is a significant factor responsible for SNHL in diabetics (chi-square test, $\mathrm{p}$ value $<0.001$ ). In our study, it was found that the severity of hearing loss was proportional to the duration of DM.

According to Sheetal Krishnappa et al, there was 63\% incidence of hearing loss in $<10$ years of duration of diabetes as compared to $85 \%$ in $>10$ years of duration. Further, as duration progressed the severity of hearing loss also increased in most of the cases.

Ashish C Agarwal et al noted that duration of DM did not have an effect on hearing status of diabetic patients.

In our study, there is a high prevalence of SNHL among uncontrolled diabetics (94.6\%) compared to controlled diabetics (20.9). The control status of DM is a significant factor responsible for SNHL in diabetics (chi-square test, $p$ value $<0.001)$.

The severity of SNHL was also high among uncontrolled DM group compared to controlled DM group.

Ashish C Agarwal et al noted that median pure tone average (PTA) values were less in patients with good glycaemic status as compared to those with poor glycaemic status.

\section{Summary}

Present study is a hospital-based cross-sectional study conducted on 200 diabetic patients attending medicine OPD. These patients were recruited to ENT Department for clinical and audiological evaluation.

It was found that greater the duration of diabetes greater is the prevalence of SNHL. In less than 5 years duration group, prevalence was $10.6 \%$. In 5 to 10 years duration group, prevalence was $38.6 \%$. In 10 to 15 years duration group, prevalence was $69.2 \%$. In more than 15 years duration group, it was $78.9 \%$. Severity of SNHL was also high among the cases with greater duration of DM.

The prevalence of SNHL was more in patients having uncontrolled diabetic status (94.6\%) compared to patients having controlled diabetic status (20.9\%). Severity was also high among uncontrolled diabetic group.

\section{CONCLUSION}

Greater the duration of DM, greater will be the prevalence of SNHL. Greater the duration of DM, higher will be the severity of SNHL. Uncontrolled diabetic status has an increased prevalence of SNHL. Severity of SNHL is high among uncontrolled diabetic group compared to controlled diabetic group.

\section{REFERENCES}

[1] Jorgensen MB, Buch NH. Studies on inner ear function and cranial nerves in diabetics. Arch Otolaryngol 1961;74:373-81.

[2] Harner SG. Hearing in adult-onset diabetes mellitus. Otolaryngol Head Neck Surg 1981;89(2):322-7.

[3] Celik O, Yalein S, Celebi $\mathrm{H}$, et al. Hearing loss in insulin-dependent diabetes mellitus. Auris Nsus Larynx 1996;23:127-32. 
[4] EL-Tabal ES, Mackenzie I, Surenthiren SS, et al. The relationship of hearing loss to age, duration, degree of control and complications in diabetic patients. Audiol Med 2003;1:242-6.

[5] Panchu P. Auditory acuity in type 2 diabetes mellitus. Int J Diabetes Dev Ctries 2008;28(4):114-20.

[6] Asma A, Azmi MN, Mazita A, et al. A single blinded randomized controlled study of the effect of conventional oral hypoglycemic agents versus intensive short-term insulin therapy on pure tone audiometry in type II diabetes mellitus. Indian J Otolaryngol Head Neck Surg 2011;63(2):114-8.
[7] Krishnappa S, Naseeruddin K. A clinical study of age related hearing loss among diabetes patients. Indian Journal of Otology 2014;20(4):160-5.

[8] Qaiyum HA, Tamkanth A, Siraj M, et al. A study on the incidence of sensorineural hearing loss in patients with diabetes mellitus. International Journal of Advanced Research 2015;3(2):685-7. 